\title{
Making News: A Successful Example of Project-Based Learning
}

\author{
Hoang Thi Ngoc Diem \\ Thainguyen University, Vietnam
}

\begin{abstract}
Project-based learning (PBL) recently has been favored by teachers using various adaptations throughout the world. The purpose of this article is to share the experience of developing language skills via a project called "Faculty Voice." In this project, second-year students of English, worked in groups as news editors to produce news; the traditional classroom environment no longer existed. The teachers gave feedback and help when students faced problems with language and technology. All activities related to the learning process were required to cover all four macroskills. Proper criteria and rubrics were also set up for assessment. At the end of the term, changes were found not only language competence and attitude, but also in some important soft skills.
\end{abstract}

\section{The Need to Change}

Through the fast development of technology, the mass media has seen great progress in their effort to satisfy a large number of customers. From a linguistic and pedagogical view, the mass media have made a great contribution to both learning materials and learning methods. In addition to using news texts adjusted for student reading materials and listening extracts, the process of students "making news" by writing, producing, and presenting their own news broadcasts has been used as a technique for them to practice and acquire a foreign language. In the movement toward innovation in language teaching at the Foreign Languages Faculty at Thainguyen University in Vietnam, making news was undertaken as a project-based learning (PBL) technique for second-year English majors with the main aim of enhancing English competence among students and experimenting with a new way of learning and teaching.

Formerly, teachers were encouraged to design their lessons in such a way that there needed to be a more communicative context for learners themselves to produce the language item after it was presented and control-practiced. This P-P-P (Present, Practice, and Produce) approach was seen as the core of communicative methodology and proved to be more effective than previous approaches. However, teaching and learning is always demanding work, and the P-P-P approach sometimes seemed inadequate. More tasks and activities needed to be integrated into the approach to create more student interaction and meaningful communication. In this age of internationalization, learners are in a more accessible world of learning, not limited to a forty-five-minute class with teachers as the only source of knowledge. The question for teachers is how to create an authentic task for students to learn and how to 
integrate students' exposure to the language into the syllabus. Among sources of access to language after school, news programs or channels in the target language appear to be common. The application of PBL is not new at the faculty (Diem, 2009), but making news as a language task had not yet been done before at the university.

\section{Features of PBL}

According to Esch (1998), PBL starts with an idea of the final result. Students must investigate the topic, plan how to achieve the desired result, and manage problems that may arise, as they would in a real-world setting. While undertaking the project, students gain a specific set of content knowledge and skills. Thomas (2000), citing Bereiter \& Scardamalia (1999), claimed that to be a PBL project, "the central activities of the project must involve the transformation and construction of knowledge. .." and added that "if the central activities. . represent no difficulty to the student or can be carried out with the application of already-learned information or skills, the project is an exercise, not a PBL project" (p. 4).

\section{Advantages of PBL}

PBL has become increasingly favored for its unique features in effectiveness and adaptability. The first outstanding advantage is its focus on content learning rather than on a specific language target. Another immediate benefit of PBL lies in its learner-centeredness. This student direction encourages students' autonomy and creativity throughout the course of the project. More critically, "PBL projects do not end up at a predetermined outcome or take predetermined paths" (Thomas, 2000, p. 4). When students can pursue their own interests and become engaged in their own learning, they discover hidden capacities that are restrained in the traditional learning context and use this area of strengths to achieve at higher levels. As a result, student autonomy and learning responsibility are developed.

Authentic integration of skills is also widely seen as a reason for PBL to be utilized. Learning in a real-life context, learners not only have authentic language input to develop their language competency, but also have opportunities to use other skills, such as those for IT, teamwork, critical thinking, and professional knowledge. The real-world connection gives students a "break from routine" (Gallacher, 2004, para. 2), as they can do something different beyond the classroom environment. This permits authentic assessment, involving the teacher and students, as well as real audiences to thoroughly assess students' end product. Another feature of PBL is that it "accommodates and promotes collaboration among students, between students and the teacher, and ideally between students and other community members as well" ("Project Based Learning," n.d., para. 6). Students learn to work in small groups that are more cooperative than competitive. Interpersonal relations are developed and gradually form the way students will work with others later in life. Finally, PBL enables students develop learning skills that will be useful beyond school.

\section{The News-Making Project}

After considering the abovementioned underpinnings and highlights, PBL was seen as a potential and practical approach and was chosen to be one of the major experiments for curriculum innovation.

\section{Participants}

The 35 intermediate-level participants were second-year full-time students at Thainguyen University. They were sampled by their own wish. These 35 students made up one class for this news project. The class met once a week for 3 periods ( 45 minutes per period) during the 
15-week term. At the beginning of the school year, all available projects were briefly described to all students, and they decided which project they wanted to do.

\section{Objectives}

The objectives of the project were to:

- Help students practice language skills via the activity of broadcasting radio news.

- Extend students' vocabulary and general understanding on various aspects of everyday life such as education, sports, culture, and the economy.

- Develop other skills such as computer skills, organizing, information processing, critical thinking, and teamwork.

- Create a real-life context for learning, and hence enhance students' confidence, autonomy, and responsibility.

\section{Procedure}

There was no textbook. Students were free to choose what they wanted to work on. In the first week, students were provided with the objectives and requirements of the project. They also grouped themselves on their own and appointed a group leader. In addition to choosing a title for their "broadcasting station," they were also required to sketch a plan for the whole term. To help them fulfill this task, a handout was delivered as a guideline, as shown in Figure 1.

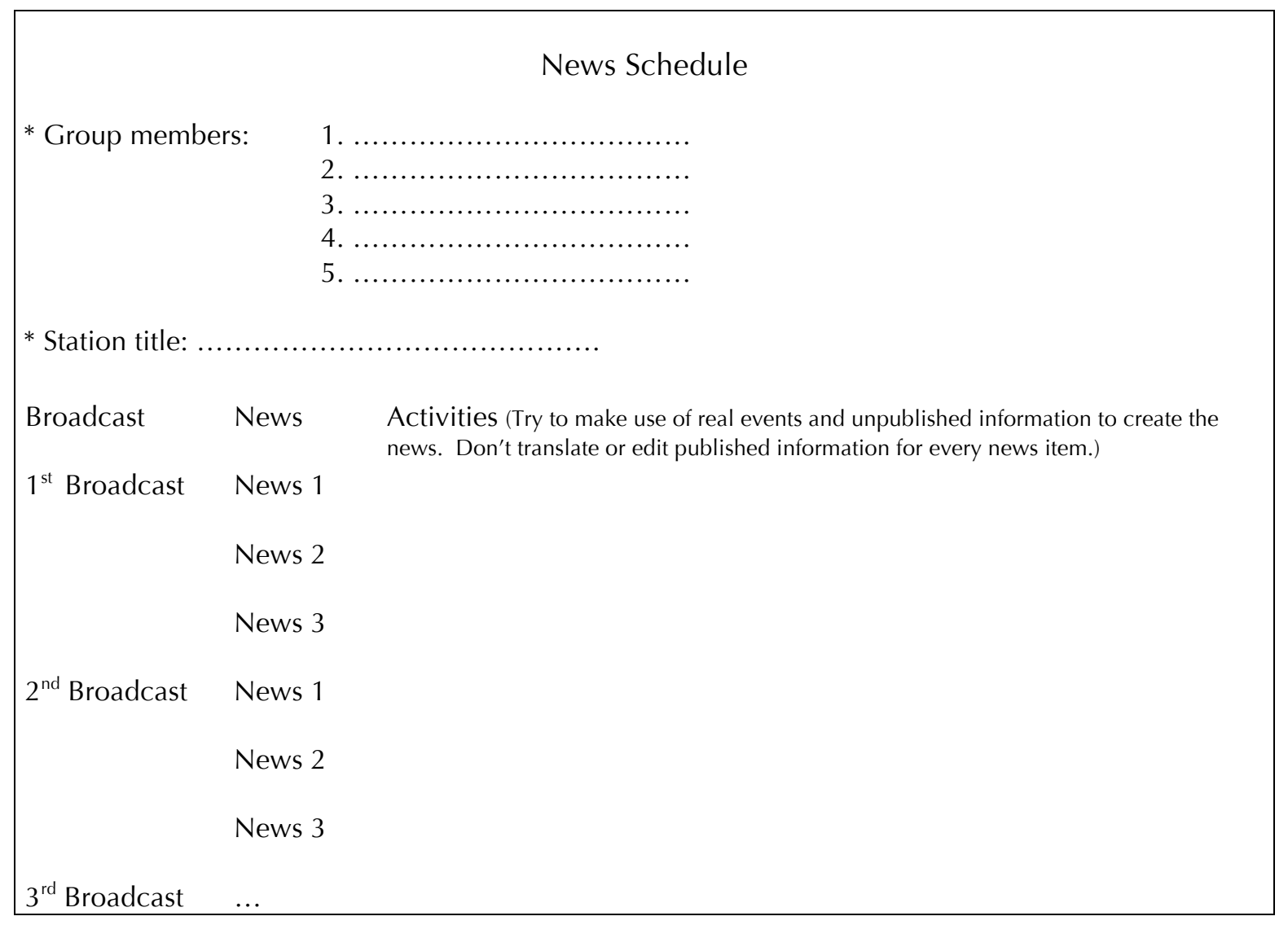

Figure 1. Project framework

This was the most important step in doing this project. As shown in Figure 1, students, working in groups, were responsible for selecting news to broadcast. They had to report real events or unpublished information. This framework was seen as the reference for students to follow throughout the term and for the instructor to use in supervising or checking the products. 
After the framework (or schedule, as it is titled in the handout) was approved by the instructor, students started working as correspondents, hunting for news, editing, and producing broadcasts. All the proposed activities to make news items and broadcasts had to meet the requirements agreed upon at the beginning of the course as follows:

\section{Project Requirements}

$\checkmark$ News reports are produced every three weeks (in 5-7 minutes) reporting events of the class / faculty / college, book reviews, film reviews, TV program reviews, tips for learning, sports, countries, tourism, health, etc. Students are free to choose the content of the news providing that it's impressive, truthful or worthwhile.

$\checkmark$ News reports are recorded and submitted to the instructors.

$\checkmark$ Recorded news is played to other students in the form of Faculty Voice during the breaks.

$\checkmark$ Opinion polls or surveys can be done to get feedback / comments from the listeners (about the content of the news and their friends' speaking skills).

$\checkmark \quad$ All members are required to read the news of the week. The name of the newsreader and reporter(s) should be mentioned.

$\checkmark \quad$ The news should follow the schedule as planned in the schedule of a week. Exceptions are allowed for news to report seasonal holidays or local events happening around the year.

$\checkmark \quad$ It should be noted that activities related to producing news must cover all four basic skills. Listening to English TV channels and English radio programs is a MUST.

$\checkmark$ It should be borne in mind that the target audience of the radio news is students of the Faculty.

Figure 2. Project requirements

Among the requirements mentioned above was a new idea proposed by the author. The project created a program that was called "Faculty Voice." Every three weeks, the complete products of all groups were broadcasted to all other students of the Faculty during break time.

\section{Project Assessments}

The products of the project were broadcasts produced throughout the term. Assessment rubrics were designed and introduced to all groups in the first week. The assessment criteria for the broadcast included a logical and cohesive schedule, delivery techniques such as sound effects and newsreader changing, pronunciation, and fluency. 


\begin{tabular}{|c|c|c|c|}
\hline \multicolumn{4}{|c|}{ Broadcast Rubrics } \\
\hline & $\begin{array}{c}\text { Excellent } \\
10-9\end{array}$ & $\begin{array}{l}\text { Poor } \\
4-0\end{array}$ & \\
\hline Criteria & Description & Comments & Grade \\
\hline Schedule & $\begin{array}{l}\text { All broadcasts are logically scheduled } \\
\text { and cohesive. } \\
\text { Newscast establishes a purpose at the } \\
\text { beginning and maintains that focus } \\
\text { throughout! } \\
\text { Work is divided fairly among } \\
\text { members. }\end{array}$ & & \\
\hline $\begin{array}{l}\text { Delivery } \\
\text { techniques }\end{array}$ & $\begin{array}{l}\text { The news item runs smoothly and is } \\
\text { clearly introduced. } \\
\text { The transfer of newsreaders is } \\
\text { professionally done. } \\
\text { Symbolic music / transfer sound is } \\
\text { used at the right time and in proper } \\
\text { ways (e.g., volume, length, and } \\
\text { rhythm). }\end{array}$ & & \\
\hline Pronunciation & $\begin{array}{l}\text { Newsreader pronounces words, } \\
\text { phrases, and sentences correctly. Few } \\
\text { mistakes are found. }\end{array}$ & & \\
\hline Fluency & $\begin{array}{l}\text { News is read naturally and fluently } \\
\text { without hesitation, repair, or redundant } \\
\text { fillers. } \\
\text { Appropriate emotions are shown in } \\
\text { corresponding news content. }\end{array}$ & & \\
\hline
\end{tabular}

Figure 3. Assessment rubrics for Faculty Voice broadcasts

Before broadcast, draft versions were submitted to the instructors, and students used the rubrics to self-assess their work. The broadcast rubrics were also employed when students peerassessed their friends' news, the audience gave feedback on "Faculty Voice," and the instructor gave final marks. Apart from broadcast assessment, other rubrics were used to assess students' portfolios (written news items to evaluate students' use of language and attitude).

\section{Teaching Approach - Instructors' Roles}

There were two instructors for this course. In this project, teachers and students no longer worked together in 45-minute lessons with textbooks. Teachers acted as instructors, giving guidance in choosing events to report, activities, and broadcast themes. More importantly, teachers prepared lessons to familiarize students with news language and structures. One structure, creating headlines, was a difficult task (headlines should be impressive and follow specialized grammatical and lexical rules). Additionally, the language features of sports news were very different from those of weather or entertainment news. Therefore, it was necessary to provide students with basic background knowledge to produce news. 
Instructors were also responsible for providing technical support. Producing a broadcast involved certain IT techniques such as editing audio files or cutting transfer music. This was not an easy task, as students worked in groups and individuals took turns reading the news items. Next, news items were edited and combined to make a complete broadcast. Not surprisingly, it took students much time to deal with technical problems. The instructors had to provide appropriate software and instructions to use the required software. It must be mentioned as well that in Vietnam, not all students could afford audio / video recorders, laptops, or even desktops; in addition, some students had limited computer skills. Therefore, before doing this project, students were required to take a compulsory course included in the curriculum, such as IT Applications in Language Learning and Teaching. The instructors were also ready to work in the computer laboratory if students needed computers for their projects.

Another important responsibility of the instructors was to give feedback and correction. Instructors and students met every week to edit news drafts, with teachers giving advice on news language, genre, news structure, and the right choice of words or expressions, along with correcting pronunciation and intonation. Using the appropriate emotions necessary for reading news was also a focus of attention and practiced by students.

The last function of the instructors was supervising. The instructors followed the newsproducing schedules proposed by "stations," checked regularly whether students were following the schedule or not, and reminded them of deadlines. The date for editing and publishing news was fixed, so students needed to be on time in writing news reports and rehearsing for broadcasts. Without the instructors' input, students might have spontaneously changed direction every time they became aware of new ideas for news stories and would likely have fallen behind schedule. It was stated, however, at the beginning of the term, that students could change the order or content of newscasts to match the seasons or local events; however, they had to inform their instructor in advance to see if it was advisable to make the change.

\section{Subject Evaluation}

At the end of the term, a subject evaluation form (see appendix) was administered to obtain students' feedback of all subjects in the term, including "Faculty Voice." Additionally, the grades of all end-of-term tests were studied to examine students' progress.

\section{Results and Discussion}

With regard to project implementation, particularly this news project, the following results were found.

Firstly, the idea of "Faculty Voice" was much appreciated by the students and seen as a stimulus for them to complete the project. More than $90 \%$ of the students highly appreciated it. They eagerly waited to listen to their voices from the loudspeaker during break time. When students were asked to give comments on the activity, some remarks were given, as summarized below:

- Students preferred feedback and comments from their friends.

- This event successfully created an enjoyable and educational atmosphere for students.

- Students realized the activities were meaningful and that they were making progress.

- They saw their work as a real show with a real audience. 
Therefore, students taking part in this project put much care and practice into producing news. They worked as real reporters.

Apart from the positive learning attitude, much progress was found in the language competence and soft skills of all students. Progress was particularly seen in the high grades they gained in the subjects of Oral Proficiency and Written Proficiency. This can be reasoned from the following points: (a) news items were products of language activities (e.g., interviewing, reviewing, conducting surveys, summarizing programs on English channels, discussing in groups, and being a newsreader) that involved the use of all four macroskills; (b) drafts were revised by peers and the instructor; and (c) proofreading was also required before broadcasting. Students also received feedback from listeners and hence accumulated experience in learning with each broadcast. Additionally, some soft skills, such as negotiation, teamwork, information processing, critical thinking, and IT were also exploited to the full and improved. In summary, the project proved to be a good chance for students to practice the use of the language.

Finally, from the observation of the author, attempting this new model helped to shape new learning methods and teaching approaches. In this textbook-free classroom, students were independent in deciding what to learn and how to learn. They worked both in groups and individually to reach the aim of the project. Their autonomy was initially established and enhanced. They no longer depended on the teacher as the only source of knowledge. Teachers, in turn, changed their traditional role to support students in the project. They worked as coordinators to moderate groups, as facilitators to provide technical support, and as instructors, supervisors, and examiners. This kind of project-based learning also required teachers to be flexible in choosing a suitable role in various situations. Teachers and students worked together, cooperated, and compromised to reach an end.

However, the author, when working as a teacher, did face some difficulties. Since students worked independently in groups both inside and outside the classroom, it was not easy to ensure the equal contribution of each group member. Some group members worked more and some less. To avoid this problem, apart from the teacher monitoring the students, the role of group leaders should be emphasized. The leaders were the ones who distributed the tasks among their group members and reported to the teacher about the performance of their friends. It also took the teacher much time to give technical support, and there was the possibility that some students' requests might go beyond the teacher's ability to solve. Therefore, it would be ideal if the institution could provide a laboratory with available equipment to help students with such projects.

The project was a part of curriculum innovation at the Foreign Languages Faculty of Thainguyen University in Vietnam, so it was an official subject in the curriculum. In other cases, where PBL is not approved to be a separate subject, there could still be many other ways to apply it. Teachers could integrate it into a certain class as practice in writing news, reading news, listening and summarizing news, or reading the news aloud, for example. From all these practicing activities, students could gather their products to make a mini broadcast. With teachers' creativity, PBL can be easily adapted to make language learning more effective and pleasurable.

\section{Conclusion}

In conclusion, PBL, although it was only experimentally integrated in the curriculum for a short period of two terms, created many changes in the faculty. Students changed their learning 
methods. Teachers changed their way of teaching. Everyone no longer depended on the traditional classroom with a ringing bell, a textbook, chalk, and a board. The impact was not only seen in those who took part in the project, but also on other students and teachers who knew about it, enjoyed its results, and observed its progress. The atmosphere of the whole faculty also changed when it was time for each new broadcast, and the project's reputation was passed by word of mouth. It is the author's personal belief that this type of learning should be employed and implemented in other subjects or with other products to motivate students in acquiring a foreign language.

\section{Author Note}

Hoang Thi Ngoc Diem, Foreign Languages Faculty, Thainguyen University, Vietnam.

Correspondence concerning this article should be addressed to Hoang Thi Ngoc Diem, Foreign Languages Faculty, Thainguyen University, Quyet Thang Commune, Thainguyen City, Thainguyen, Vietnam. E-mail: ngocdiemvn@gmail.com 


\section{References}

Diem, H. T. N. (2009). Magazine as project-based learning. In S. Rilling \& M. Dantas-Whitney (Eds.), TESOL Classroom Practice Series: Authenticity in the Classroom and Beyond: Adult Learners (pp. 37-45). Alexandria, VA: TESOL, Inc.

Esch, C. (1998). Project-based and problem-based: The same or different? Redwood City, CA: San Mateo County Office of Education.

Gallacher, L. (2004, March 23). Project work with teenagers. Retrieved from http://www.teachingenglish.org.uk/articles/project-work-teenagers

Project based learning. (n.d.). Retrieved from http://www.neiu.edu/ middle/Modules/Middle\%20mods/PBL/project\%20based.html

Thomas, J. W. (2000). A review of research on project-based learning. San Rafael, CA: Autodesk Foundation. 


\section{Appendix \\ Subject Evaluation Form}

Subject:

Group:

Teacher:

Semester/Academic year:

Read the following statements carefully and give your idea by ticking in the appropriate box.

$\begin{gathered}\text { Strongly } \\ \text { agree }\end{gathered}$
Agree Disagree No idea

Teaching Methods

(1) The teaching methods of this subject are suitable.

(2) I will apply some of the similar methods to my future teaching.

(3) The teacher made proper integration between introducing new subject matters and revising the old ones.

Teaching Materials

(4) Supplementary materials from the teacher were more interesting than the course book.

(5) All the materials used in class were challenging but suitable with the subject.

(6) All these materials will be useful for my future teaching.

General Comments

(7) This subject is very important in language teaching and learning.

(8) The final assessment mark precisely reflected my knowledge of the subject.

(9) My knowledge was much improved at the end of the subject.

Other comments: 